\title{
La construcción del periodismo "localizado" en medios digitales europeos. Estudio de casos
}

\section{Shaping a "localized" journalism in European digital media. A study of cases}

Rubén Rivas-de-Roca. Universidad de Sevilla. España.

rrivasderoca@us.es

$[\mathrm{CV}]$ (D)

Mar García-Gordillo. Universidad de Sevilla. España.

marggordillo@us.es

[CV] 1 C

Francisco J. Caro-González. Universidad de Sevilla. España.

fjcaro@us.es

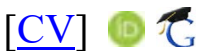

Este artículo se enmarca dentro VI PPIT-US (Plan Propio de Investigación y Transferencia de la Universidad de Sevilla), mediante el Contrato Predoctoral para el Desarrollo del Programa Propio I+D $i$ de la US en Áreas de Especial Atención (2017) asignado al Departamento de Periodismo II, que tiene como beneficiario a Rubén Rafael Rivas de Roca García.

- Inicio de la investigación: 01/07/2018

- Término de la investigación: 07/11/2018

Cómo citar este artículo / Referencia normalizada

Rivas-de-Roca, R., García-Gordillo, M. y Caro-González, F. J. (2020). La construcción del periodismo "localizado" en medios digitales europeos. Estudio de casos. Revista Latina de Comunicación Social, 75, 1-26. https://www.doi.org/10.4185/RLCS-2020-1414

\section{RESUMEN}

Introducción: La información de proximidad se perfila como un elemento político central en la construcción de comunidades locales en la Red. En un contexto hiperconectado, queremos conceptualizar una modalidad de servicio público: el periodismo "localizado". Metodología: En este artículo se emplea la estrategia de investigación del estudio de casos para valorar la "localización" informativa de la Unión Europea en tres cibermedios locales de diferentes países: Berliner Zeitung, This is Local London y Sevilla Actualidad. Esta aproximación empírica mediante el análisis de casos sirve para enmarcar una revisión crítica de la literatura sobre información local. Resultados y discusión: Se aprecia superficialidad y falta de lenguajes digitales en los ejemplos. Esto puede ser contrarrestado con una información sencilla y práctica, como refleja el texto de This is Local London sobre el cambio de hora europeo. La información "localizada" requiere vocación utilitarista y nuevas fórmulas que conecten más con la audiencia, como las narrativas transmedia.

PALABRAS CLAVE: periodismo local; cibermedios; Berliner Zeitung; This is Local London; Sevilla Actualidad. 


\begin{abstract}
Introduction: Local journalism is emerging as a central political element in the shaping of local communities on the Internet. In an hyperconnected context, this research aims to conceptualize a form of public service: "localized" journalism. Method: This paper employs the study of cases research strategy to assess the journalistic "location" of the European Union in three local digital media from different countries: Berliner Zeitung, This is Local London and Sevilla Actualidad. This empirical approach through the study of cases works as a frame for a critical review of the literature on local journalism. Results and discussion: Superficiality and lack of digital languages are found in the examples. This can be counteracted by simple and practical information, as showed in the analyzed text of This is Local London addressing European seasonal clock change. The "localized" information requires a utilitarian view and new formulas that connect more with the audience, like transmedia narratives.
\end{abstract}

KEYWORDS: local journalism; digital media; Berliner Zeitung; This is Local London; Sevilla Actualidad.

\title{
CONTENIDOS
}

1. Introducción. 1.1. Trayectoria de la prensa local. 1.2. Los nuevos diarios digitales locales. 1.3. Lenguaje, funciones, tratamiento y contenidos. 1.3.1. Lenguaje. 1.3.2. Funciones. 1.3.3. Tratamiento y contenidos. 2. Método. 3. Casos de estudio. 3.1. Berliner Zeitung. 3.2. This is Local London. 3.3. Sevilla Actualidad. 3.4. Estudio comparativo ante el cambio de hora europeo. 4. Análisis de resultados. 4.1. Características de los cibermedios locales analizados. 4.2. Conceptualización de un periodismo "localizado" a escala europea. 5. Discusión y conclusiones. 6. Notas. 7. Fuentes. 8. Referencias bibliográficas

\section{Traducción del resumen de R. Rivas-de-Roca}

\section{Introducción}

El concepto de local está ligado al periodismo desde sus orígenes. El poder ha necesitado siempre comunicarse con sus administrados más próximos, a la vez que estos requerían dicha información para poder actuar en consecuencia. Varios estudios clásicos (Park, Burgess y McKenzie, 1974; McQuail, 1994) señalan la influencia de los medios en el conocimiento acerca del entorno. Para esta labor social de vigilancia del poder, construcción de la realidad y mediatización de los asuntos públicos cercanos, el área de especialización periodística por excelencia es la información política (Gainous y Wagner, 2013), adaptada en este caso a un enfoque local.

En un mundo occidental marcado por la globalización, que ha supuesto una quiebra de las barreras geográficas y temporales, la prensa local no solo mantiene su importancia, sino que avanza posiciones en los últimos años (López García, 2008). A pesar de los problemas económicos que han afectado a los medios, estudios como los de Möhring recogen que, en países como Alemania, "la prensa local continúa siendo la más importante y fiable fuente de información para más del $50 \%$ de la población" (2015, p. 15).

Las nuevas modalidades de consumo de noticias (López García, 2015; Yunquera Nieto, 2016), no han conllevado una pérdida de interés por lo local; más bien al contrario. Ante la vorágine informativa de canales y contenido, el ciudadano de a pie necesita saber qué ocurre en su entorno más propio, algo que imbrica con el llamado periodismo de servicio (Diezhandino, 1994). La información de cercanía desempeña así una función social clave en las comunidades locales "ya que las percepciones de pertenencia, identidad o comunidad se encuentran fuertemente mediatizadas: los 
medios locales proporcionan la columna vertebral informativa de lo que la gente sabe sobre la vida social en su ciudad" (Leupold, Klinger y Jarren, 2018, p. 960).

En los últimos años, el periodismo local se ha enfrentado a una serie de desafíos en esta cobertura, definidos por la disminución del número de lectores, la pérdida de ingresos o la concentración mediática. Esta situación coincide con una devaluación en las ciudades del concepto de calidad de la cohesión social, popularizado por Emile Durkheim (Novy, Swiatek y Moulaert, 2012, p. 1875). Este deterioro viene ejemplificado por la gentrificación o la pérdida de espacios comunes de socialización, lo que abarca desde los sindicatos de clase a las organizaciones vecinales. Sin embargo, los medios locales, y especialmente los nativos digitales, se han convertido en nodos imprescindibles para la circulación de noticias sobre asuntos de proximidad (Leupold, Klinger y Jarren, 2018).

Existe un cierto debate sobre si se debe seguir hablando de prensa local cuando gracias a Internet cualquier contenido producido en un entorno próximo se puede viralizar hasta alcanzar una repercusión global. Desde el Centre for Community Journalism de la Universidad de Cardiff se afirma que lo único de local que conserva la prensa de proximidad es el nombre, bajo la denominación de "local name only" (Franklin, 2006). En cambio, académicos como Nielsen subrayan que "sigue habiendo prensa local, puesto que el factor diferencial es el tratamiento de la información" (2015, p. 6). Así pues, la revolución digital ha provocado que los medios del periodismo de proximidad ya no tengan una difusión estrictamente local, pero sí practican una cobertura de la realidad desde planteamientos locales, diferenciándose del resto de empresas del panorama informativo.

La necesidad de información local es patente y en este contexto de cambio las empresas periodísticas tienen que innovar en diferentes niveles para aportar valor añadido a grupos de lectores con interés común en la información de un territorio geográfica y políticamente delimitado. Los medios locales deben esforzarse en identificar y satisfacer de forma rentable las expectativas informativas de estos lectores mediante la innovación. La OCDE", entiende por innovación "la concepción e implantación de cambios significativos en el producto (servicio), el proceso, el marketing o la organización de la empresa con el propósito de mejorar los resultados" (2018, p. 45).

Los cambios innovadores deben ser "significativos"; esto supone modificar sustancialmente lo que se estaba haciendo hasta ahora. Las pequeñas mejoras no pueden ser consideradas innovaciones. Difundir noticias a través de Twitter, sin más, no es una innovación. El fin de la innovación es influir positivamente en los resultados de la empresa periodística local, ya sea mediante la reducción de costes o el incremento de calidad del servicio informativo entendida como satisfacción de las expectativas de los sus públicos. Innovar, en definitiva, es crear valor relevante y único. Relevante para que tenga impacto en el grupo social al que se dirige y único para poder diferenciarse de otros medios de comunicación con las que compite.

El enfoque desde parámetros de cercanía funciona como elemento característico de lo que se ha considerado tradicionalmente prensa local. Partiendo de esta premisa, este artículo tiene como objetivos 1) realizar una revisión crítica de la literatura científica sobre cibermedios locales, especialmente en lo referente a la innovación en la información política; 2) delimitar el concepto de periodismo "localizado" en el contexto de los medios digitales, entendido como un tratamiento que aborda desde el plano de la proximidad los asuntos globales; 3) conocer las estrategias "localizadas" innovadoras de medios digitales de amplio recorrido a nivel europeo; y 4) llevar a cabo un análisis

\footnotetext{
${ }^{1}$ Organización para la Cooperación y el Desarrollo Económicos (OCDE): agrupa a 37 países miembros y su misión es promover políticas que mejoren el bienestar económico y social de las personas alrededor del mundo.
} 
comparado de las innovaciones informativas de iniciativas localistas en distintos puntos del continente.

Para el estudio de casos se han seleccionado las informaciones publicadas sobre asuntos europeos (Unión Europea), durante un período trimestral, por tres medios locales digitales de consolidada trayectoria: Berliner Zeitung (Berlín), This is Local London (Londres) y Sevilla Actualidad (Sevilla). Se trata de iniciativas periodísticas que cuentan con relevancia social y profesional, representando ciudades de distinto tamaño y en diferentes países europeos. En el estudio de casos también se analizará la cobertura "localizada" que estos tres medios otorgan a un tema común vinculado a la Unión Europea.

\subsection{Trayectoria de la prensa local}

La prensa local no es un fenómeno nuevo, sino que constituye en realidad el origen de todo el periodismo (Nielsen, 2015; Napoli et al., 2017). La vocación local y el compromiso con sus ciudades se encuentra inserto en algunos de los diarios con mayor trayectoria histórica a nivel mundial, como The Times (Londres), The Washington Post (Washington) o The New York Times (Nueva York). Este es también el caso del extinto Diario de Barcelona, fundado en 1792 y considerado el primer periódico de Europa continental. La proximidad se revela, por tanto, como una de las características esenciales del periodismo, ocupando posiciones centrales de la comunicación mediada desde los mismos inicios de la misma.

La prensa regional y local supone un fenómeno con importancia en toda Europa, pero López García y Maciá Mercadé indican que es mayor "de forma significativa, en Francia, Alemania, Italia, Suiza y España -la mayoría de las cabeceras españolas son locales o regionales y tienen más del doble de lectores-" (2007, p. 37). Tanto en Alemania (Ley Fundamental de Bonn de 1949) como en España (Constitución Española de 1978), la creación de constituciones democráticas y descentralizadoras en la segunda mitad del siglo XX favoreció que se desarrollase una base de medios regionales y locales impresos muy asentados.

Existen variaciones considerables en cómo se han desarrollado los medios locales y regionales en el mundo occidental desde la posguerra. Mientras que, como hemos visto en Alemania y España se despliega un mercado mediático plagado de medios de proximidad, en Reino Unido predomina un sistema de medios más orientado a la totalidad del país. Nielsen explica buena parte de esta diferencia por la divergencia estructural que presenta el sistema político federal alemán con uno más centralizado, como sería el caso de Reino Unido; aunque prácticamente en toda Europa occidental se produce un fenómeno de concentración en la propiedad de la prensa local $(2015$, p. 57).

Si bien lo local ha estado presente desde el nacimiento de la prensa europea, la historia de los medios muestra etapas muy distintas a la hora de prestar atención al ámbito de la proximidad. El interés por los asuntos cercanos se ha incrementado en los últimos años de forma correlativa a la emergencia de las nuevas tecnologías, hasta tal punto que lo local está presente en todo tipo de noticias (Lauterer, 2006). Un ejemplo de ello es la gran importancia que las autoridades locales conceden a lo que se publica en los medios de proximidad (Firmstone y Coleman, 2014).

En un contexto de audiencias fragmentadas, los medios locales, y en particular los digitales, son los únicos que consiguen mantener un elevado nivel de compromiso por parte de sus públicos (Leupold, Klinger y Jarren, 2018). Ya a finales del siglo XX se apuntaba que en Europa los medios regionales (por locales) gozaban de mejor salud que los de circulación nacional (De Fontcuberta, 1997). El éxito 
se debía a que cultivaban el factor de la proximidad, considerado uno de los reclamos más poderosos a la hora de elegir una noticia, a la vez que son reflejo de una fuerte conciencia de identidad regional.

En el caso de España, en 2018 los medios locales suponían el 73,7\% de los cibermedios, mientras que los de alcance nacional e hiperlocal -referida a las publicaciones de barrio o distrito- significaban solo el 23,8\% y el 2,4\% respectivamente (Salaverría, Martínez-Costa y Breiner, 2018). Por tanto, lo local tiene una presencia preponderante en el panorama ciberperiodístico español, mucho mayor que el número de cabeceras locales que podamos encontrar en un kiosco de prensa tradicional.

La información local ha cobrado fuerza como respuesta a la estandarización comunicativa global. Es una alternativa que satisface la necesidad social de una identidad autóctona ante la homogeneización cultural de la globalización y que garantiza la no dependencia del mensaje comunicativo respecto de los grandes grupos de poder mediático. Una de las vías para resistir frente al poder de los grandes poderes mediáticos, surgidos a partir del fenómeno de concentración empresarial, es la búsqueda de formas alternativas de comunicación en pequeña escala (López García, 2008).

Los medios locales poseen una serie de características intrínsecas que los fortalecen frente a sus competidores, como son su arraigo al territorio, una gran proximidad al público que se siente identificado con sus contenidos, o un alto grado de flexibilidad empresarial (González Esteban, 2009; Carson et al., 2016). No obstante, en la sociedad actual todas estas potencialidades solo pueden ser aprovechadas si se apuesta claramente por innovar en formatos online, algo que ya era mencionado en la literatura hace una década (González Esteban, 2009, p. 161).

Las propias políticas comunicativas de la UE van dirigidas desde 2010 al impulso de los ámbitos de proximidad, como evidencia la Conferencia Anual de Comunicación Pública Europea que organiza desde ese año el Comité Europeo de las Regiones (Europcom). A escala global, el fenómeno de acercar la realidad a través de un periodismo cercano de servicio público se experimenta desde los años 90, en respuesta al déficit histórico periodístico de excesiva distancia percibida entre los medios de comunicación y las audiencias a las que sirven (McCollough, Crowell y Napoli, 2016, pp. 2-3).

\subsection{Los nuevos diarios digitales locales}

La información local ha sido definida como "el área periodística que recoge los acontecimientos producidos en una determinada zona y afectan a su política, urbanismo, ecología, costumbre y realidad sociocultural" (Esteve Ramírez, 2002, p. 484). Informar a las personas con las que se comparte el espacio ciudadano supone una doble exigencia para los periodistas. Por un lado, exige un mayor conocimiento de lo que es relevante para sus conciudadanos. Por otro, la rendición de cuentas es más clara y directa que en otras modalidades periodísticas (Izquierdo Labella, 2010, p. 16).

De acuerdo al planteamiento clásico del sociólogo norteamericano Robert E. Park (Berganza Conde, 2000), el periódico intenta reproducir en la ciudad las condiciones de la aldea primitiva que suponía la primera forma de organización humana. Partiendo de esta premisa, el espacio de especialización periodística que mejor se ajusta a esta función es la información local, puesto que "el área local posibilita un conocimiento de la realidad concreta similar al de la aldea en la que todo el mundo se conoce" (Esteve Ramírez y Fernández del Moral, 2009, p. 75).

En una situación ideal, la información política debería ser el eje en torno al que pivotaran los medios digitales, en tanto en cuanto el periodismo constituye el sustento de la democracia, en este caso de la esfera pública local (McNair, 1999). La política municipal o regional supone una de las principales 
temáticas, aunque la prensa local ha tendido históricamente a otorgar una gran importancia a otros ámbitos, como la cultura, el deporte o los sucesos (Esteve Ramírez y Fernández del Moral, 2009)

La sociedad digital ha traído consigo una recuperación de los espacios centrales para este periodismo político local (Nielsen, 2015). Internet se caracteriza por unos principios comunitarios que imbrican con el sentimiento de una sociedad local, en la cual sus integrantes son participantes relativamente activos en lo que sucede en su entorno más cercano. La prensa local ya no está determinada únicamente por la difusión territorial, sino por el ámbito de proximidad de su cobertura mediática, a la que también atañen los problemas de las personas que, siendo originarios de ese lugar, viven en estos momentos fuera de tal espacio geográfico.

En este contexto digital, en el que las redes sociales tienen incluso capacidad de movilizar el voto (Alonso-Muñoz y Casero-Ripollés, 2017), la información de proximidad ha pasado a ser más importante para los ciudadanos, puesto que es la forma de poder participar en los asuntos de la comunidad local. Se trata de un cambio de paradigma de la comunicación global, que camina hacia postulados más integradores que los medios digitales tienen que atender.

La figura por antonomasia de este sector es el cibermedio local. Los cibermedios han sido catalogados como medios de comunicación que utilizan "una plataforma digital interactiva en línea, bien en forma de sitio web o bien en forma de aplicación para la web móvil" (Codina et al., 2014, p. 4). Por tanto, el elemento distintivo de este nuevo actor es su versión online, de tal forma que la edición digital de un periódico tradicional es considerada un cibermedio.

Por su parte, por medios locales digitales Salaverría, Martínez-Costa y Breiner entienden "todos aquellos comprendidos desde los medios municipales hasta los medios orientados a toda una comunidad autónoma, pasando por los medios comarcales y provinciales" (2018, p. 1043). Esto significa que de nuevo el enfoque vuelve a erigirse como el rasgo identitario de los medios locales, si bien las TIC implican una revolución en lenguajes y formatos que será valorada en el siguiente apartado.

En el mundo occidental, las nuevas tecnologías han supuesto para la mayor parte de la población la posibilidad de disponer de un amplio abanico de fuentes de información, donde se enmarcan los cibermedios locales. Este acceso libre ha menguado la brecha existente entre la prensa de prestigio y la otrora humilde prensa local. Internet promueve la interacción a través de un cierto feedback usuarioreceptor, que convierte a este último en miembro de una comunidad de lectores. Algunos investigadores hablan incluso de la democratización de las sociedades que puede conllevar la Red (Lewis, Kaufhold y Lasorsa, 2010; Ihlebæk y Krumsvik, 2015). Sin embargo, la variedad informativa se perfila como limitada: la explosión digital en el número de cabeceras no ha supuesto una mayor variedad en las temáticas de las noticias (Boczkowski y De Santos, 2007; Welbers et al., 2018).

En consecuencia, los medios digitales no conceden los espacios a la pluralidad de fuentes que se les suponía. Además, la presencia de las agencias como fuente es mucho mayor en los diarios digitales publicados en línea que en los periódicos tradicionales (Welbers et al., 2018, p. 317). La razón se halla en que buena parte de la prensa digital carece de los recursos necesarios para disponer de fuentes propias.

\subsection{Lenguaje, funciones, tratamiento y contenidos}

\subsubsection{Lenguaje}

Los medios locales se focalizan en temas próximos que pueden ser de interés para los habitantes de una determinada área geográfica local. Se trata de una forma de "ganar espacio/tiempo para esos 
asuntos mientras excluyen de la oferta informativa o les dedican poca atención a otros acontecimientos actuales” (López García y Maciá Mercadé, 2007, pp. 35-36).

Estos temas cercanos son tratados mediante un lenguaje singular, más directo e informal que el de la prensa de referencia nacional. Los medios locales son pioneros en cuanto a introducir innovaciones en formatos para enfatizar contenidos en el panorama mediático, si bien la utilización de unas modalidades $\mathrm{u}$ otras no contribuye directamente a una mayor cohesión social (Leupold, Klinger y Jarren, 2018, p. 970). La variedad empleada se sintetiza en cuatro géneros fundamentales: "la noticia, el reportaje, la crónica y el artículo o comentario" (De Fontcuberta, 1997, p. 104). Hay autores que a esos cuatro incorporan la entrevista, por su elevado grado de presencia en el periodismo de proximidad (López García y Maciá Mercadé, 2007, p. 100).

Desde la academia se sostiene que la información local se caracteriza por una multiplicidad de modalidades expresivas (Möhring, 2015; Leupold, Klinger y Jarren, 2018). Entre ellas, los artículos y las entrevistas poseen una mayor preponderancia que otras áreas de especialización periodística. La razón probablemente se encuentre en que estos géneros demuestran una gran cercanía con el lector que, por otra parte, debería ser básica en una prensa que se define como "local". Tanto el artículo como la entrevista suponen la interpelación directa con personas identificadas por nombres y apellidos que tienen una opinión sobre lo que sucede en el ámbito de la proximidad.

En cuanto al lenguaje con que se emplean esos géneros, los medios locales digitales, y especialmente los nativos, presentan las características propias del ciberperiodismo: hipertextualidad, multimedialidad e interactividad (García de Torres y Pou Amérigo, 2003). Además, se aplican las fórmulas básicas de los géneros periodísticos en Internet, que pasan por el empleo de título enlace, datación exhaustiva, fragmentación hipertextual, párrafo de enganche y enlaces documentales (Salaverría, 2005).

No hay duda de que la introducción de las nuevas tecnologías digitales ha dado lugar a innovaciones en el proceso de producción de la noticia. Internet obliga a establecer horarios de día completo para poder nutrir de información a la página web. También supone la traslación de aspectos asociados históricamente a la prensa local, como la interactividad o el lenguaje cercano derivado de la cercanía, al conjunto de las publicaciones digitales. La distancia ha sido dinamitada por la Red de redes, dado que ahora es posible interaccionar a tiempo real con periodistas situados a miles de kilómetros. El mundo digital exige hipertextualidad, imágenes y un lenguaje más conciso, características que pueden haber influido a todo el periodismo, incluido el publicado en papel (Welbers et al., 2018).

\subsubsection{Funciones}

La prensa local tiene unas funciones específicas dentro de la labor social del periodismo. De acuerdo a Schudson, el periodismo en sí implica una serie de funciones adherentes: proporcionar información, investigar, analizar, crear empatía social, servir como foro público y hacer funcionar la democracia representativa $(2008$, p. 24). Las categorías de Schudson son importantes porque brindan un marco conceptual para entender la forma en la que el periodismo fortalece una sociedad democrática. Estas atribuciones no se encuentran necesariamente limitadas a los medios de comunicación tradicionales, sino que son aplicadas a las redes sociales y a las plataformas de noticias hiperlocales (Carson et al., 2016, p. 134)

En el ámbito de la proximidad se perciben una serie de funciones ad hoc del periodismo. López García y Maciá Mercadé detallan cuatro cometidos propios de esta especialización periodística: exposición al receptor de lo que ocurre en su entorno más cercano, profundización en temáticas 
propias del área local, estrecho contacto con el usuario y fomento de la participación democrática (2007, pp. 22-23). Desde el punto de vista del valor del periodismo en la democracia (McNair, 1999), esta última función resulta la más importante y se deriva de la capacidad que estos medios tienen para despertar interés por los asuntos locales.

Un objetivo informativo clásico de la prensa local es ofrecer información de servicio público. Esto supone proporcionar datos que resultan útiles para los ciudadanos de ese entorno, tales como agenda cultural, horarios de transportes públicos o la previsión del tiempo. Esta información de servicio pervive pese a los cambios tecnológicos y es uno de los factores que convierte a los medios locales en fundamentales para entender lo que sucede en una ciudad (Hess y Waller, 2016, p. 264). El periódico de masas ha tenido una finalidad de servicio desde su nacimiento en el siglo XIX, que no se debe confundir con el llamado periodismo "de servicio", entendido como categorización propia por Diezhandino (1994).

\subsubsection{Tratamiento y contenidos}

Los periodistas locales deben valorar una serie de criterios para determinar cuáles son los hechos noticiables que pueden acabar convertidos en información periodística. Este contenido tiene que estar en consonancia con la pretensión de funcionar como reflector de la sociedad local de la que forma parte, para lo cual Armentia Vizuete y Caminos Marcet establecen quince principios que imbrican con la variable afectiva del lector (2003, pp. 126-127). Se trata siempre de una información que genera expectativas presentes y futuras para los miembros de esa comunidad.

Los contenidos de la prensa local buscan identificarse con los intereses de los ciudadanos. Esta es la razón de ser del periodismo de proximidad. El profesor Bel Mallén introduce el concepto de subsidiaridad en este ámbito, en tanto en cuanto el desarrollo de los medios locales ha posibilitado que se "reflejasen las preocupaciones e intereses más directamente sentidos por los habitantes de dichos núcleos, muchas veces olvidados por los contenidos informativos de los medios de ámbito nacional" (2002, p. 28). Por tanto, los diarios de proximidad cumplen una función de profundización en la realidad local que difícilmente se va a ver satisfecha por la prensa nacional. El principio de subsidiaridad invitaría a cada medio a dedicarse exclusivamente a aquello que mejor cubre, no invadiendo competencias de espacios periodísticos superiores o inferiores en dimensión geográfica.

Por contenido, la prensa local es la que mejor cumple la tesis clásica en periodismo de construir comunidad en su zona de difusión (Novy, Swiatek y Moulaert, 2012). Tanto en la década de los noventa como en el siglo XXI se han efectuado investigaciones en Estados Unidos y Europa que han mostrado en sus resultados como más del $60 \%$ de los ciudadanos prefiere la prensa local para recibir información (Möhring, 2015).

Con respecto al origen de la información, Napoli et al. sostienen que existe una relación entre el tamaño de la población y la cantidad de fuentes que emplea un periodista local $(2017$, p. 380). A más población es lógicamente mayor el número de fuentes de consulta que el autor de la información tiene a su disposición. En las últimas décadas se ha producido una profesionalización de las fuentes institucionales, con una proliferación de gabinetes de comunicación que filtran la información y asesoran a las entidades locales y regionales (Rodríguez Rey et al., 2015). El propósito último de estos gabinetes es situar el mensaje de sus instituciones en los medios de proximidad, lo que no favorece siempre que los ciudadanos reciban una mejor información.

A pesar de la profesionalización de las fuentes, la relación directa y la capacidad del periodista de tejer redes de contacto interpersonales siguen teniendo una gran trascendencia en los escenarios de 
proximidad. El número y calidad de fuentes de proximidad resulta determinante para obtener informaciones que resulten provechosas, para lo que son claves las fuentes propias. Así lo atestigua también una investigación de McCollough, Crowell y Napoli:

Nuestros resultados también indican la importancia de las redes interpersonales a nivel local.

A pesar de la proliferación de tecnologías, plataformas y opciones de contenido a las que los

miembros de la comunidad pueden recurrir en busca de noticias e información locales, las

redes interpersonales parecen ser un medio vital para que los miembros de la comunidad se

mantengan informados". (2016, p. 23)

El consumo de noticias sobre ámbitos locales en la Red se encuentra bastante "auto-dirigido", puesto que es el ciudadano el que teje una estrategia individual para informarse (Hume, 2012). La centralidad de los vínculos interpersonales en las discusiones sobre las noticias locales probablemente se encuentra motivada por el propio carácter cercano y a menor escala de estas informaciones, definidas por Byerly (1961) como "nearness to people" (cercanía a las personas), en una acepción recogida ampliamente en la literatura (Robinson, 2014, p. 113).

Uno de los aspectos que el periodista local debe tener más claro en el tratamiento informativo es que el sujeto objeto de su información supone un ser muy cercano a su labor profesional (Barnett y Townend, 2015). Al contrario de lo que ocurre en el ámbito de la información nacional y, por supuesto, internacional, la relación directa entre sujeto y objeto informativo es tan evidente y fuerte que puede condicionar a la propia información. Por ello, el informador local tiene que desarrollar una capacidad aún mayor de resistencia a las presiones políticas, sociales y económicas que en otros campos informativos. El hecho de que aquel que ha sido objeto de su actividad informativa sea una persona cercana y con la que deba mantener una relación estrecha, no puede marcar negativamente su quehacer informativo.

\section{Método}

En el presente artículo se elige la metodología del estudio de casos múltiples para lograr los objetivos de la investigación. Autores del área académica de comunicación (García Avilés y Carvajal, 2008; Gómez-Diago, 2010) sostienen que este tipo de métodos permiten conocer mejor las porosas realidades mediáticas actuales al romper la dicotomía entre lo cuantitativo y lo cualitativo. El estudio de casos posibilita la combinación de estrategias multimétodo, que en esta investigación pasan por el análisis de contenido y el estudio sistemático de los medios seleccionados a través de la consulta de sus publicaciones sobre la UE durante tres meses -julio a septiembre 2018-. La elección de este tema se encuentra motivada porque se trata de una cuestión lejana que, sin embargo, tiene importantes consecuencias en el día a día de los ciudadanos y, por tanto, puede ser objeto de "localización".

Además de efectuar una revisión crítica de la literatura científica sobre cibermedios locales -realizada en el apartado introductorio y que se pondrá en común con los resultados obtenidos-, este artículo tiene como objetivo principal:

OP: Delimitar el concepto de periodismo "localizado" en los medios digitales.

De este objetivo general se derivan dos de naturaleza secundaria:

OS1: Conocer las innovaciones realizadas en fórmulas "localizadas" empleadas por medios digitales consolidados a nivel europeo. 
OS2: Analizar comparativamente las prácticas informativas con un mismo tema de iniciativas mediáticas locales en distintas partes de Europa.

Los cibermedios escogidos son Berliner Zeitung (Berlín), This is Local London (Londres) y Sevilla Actualidad (Sevilla). Para su selección se han considerado los siguientes criterios:

- Medios procedentes de países que se adhirieron en diferentes momentos históricos a la Unión Europea. Esto explica la pertinencia de comparar Alemania -uno de los estados fundadores de las Comunidades Europeas en 1957- con países sumados posteriormente, caso de Reino Unido en la primera adhesión (1973), y de España en 1986, siguiendo la ola democrática en los países del sur de Europa. Además, Reino Unido se encuentra en vías de abandonar la UE, lo que singulariza aún más su relación con el proyecto europeo.

- Cibermedios adscritos, tanto por su título como por su línea editorial, a capitales o ciudades de gran tamaño. Estos diarios digitales deben ejercer una cobertura local de los hechos, no siendo válidas fórmulas hiperlocales, ya que partimos de la premisa de que la prensa de barrio no va a tratar asuntos lejanos y, por ende, a necesitar "localizar". Debido a ello se seleccionan medios de Berlín y Londres, así como de Sevilla en lugar de Madrid, puesto que en la capital española no se observan propuestas periodísticas para toda la ciudad, sino por distritos.

- Medios consolidados, que gozan ya de un cierto recorrido en el panorama mediático de sus ciudades. Por "medios consolidados" se entienden aquellos que han sido creados hace más de 5 años, un espacio temporal que nos permite discernir iniciativas informativas locales afianzadas de otros proyectos digitales en vías de asentamiento.

- Se busca la selección de medios nativos digitales, dado que a priori presentan mayores niveles de usabilidad e interactividad que aquellos que se han sumado al mundo digital posteriormente (Costa Sánchez, 2012). Esto resulta posible en Londres y Sevilla, pero no en Berlín, donde las iniciativas nativas se circunscriben al plano de lo hiperlocal. Por ello, para la capital alemana se ha escogido un cibermedio derivado de un periódico tradicional Berliner Zeitung-, basándose en un criterio de audiencia online; es el medio local berlinés con mayor número de visitas web.

Por otro lado, el análisis de contenido sirve para efectuar una comparación de cómo estos tres diarios abordan una temática internacional que tiene aplicaciones locales. Se ha seleccionado como tópico la propuesta de cambio de hora de la Comisión Europea, asunto que ha despertado un gran interés en la opinión pública del continente. El objetivo es discernir hasta qué punto estos medios "localizan" o no, es decir, si proporcionan herramientas para una interpretación de los hechos generales desde parámetros de proximidad.

El análisis se aplica sobre una muestra de informaciones sobre asuntos europeos recogida durante tres meses -julio, agosto y septiembre de 2018-, seleccionados porque es el momento en que se produce una decisión de enorme impacto como es la propuesta del cambio horario. La muestra asciende a un total de 250 textos periodísticos: 135 de Berliner Zeitung, 99 de This is Local London y 16 de Sevilla Actualidad.

Este estudio se desarrolla sobre seis variables: autoría, género, fuentes, enfoque (internacional, nacional o local), grado de contextualización y empleo de herramientas ciberperiodísticas, ya sean tradicionales (título enlace, datación exhaustiva, fragmentación hipertextual, párrafo de enganche y enlaces documentales) o novedosas (narrativa transmedia).

No pretendemos conocer el tratamiento periodístico que los medios digitales seleccionados otorgan a un tema, para lo que haría falta un análisis de contenido sistemático durante un espacio más amplio 
de tiempo, sino utilizar ejemplos de estos medios influyentes para conceptualizar un área de especialización que va más allá de la información local: el periodismo "localizado".

\section{Casos de estudio}

\subsection{Berliner Zeitung}

Alemania es uno de los países europeos donde los medios de comunicación han tenido tradicionalmente una mayor importancia para la sociedad (Seidendorf, 2007). Esto no impide que, de acuerdo a los datos de Statista $\mathrm{GmbH}$, la venta de periódicos haya descendido entre 1991 y 2015 en más de 10 millones de ejemplares, pasando de 27,3 millones a 16,1 millones. La mayoría de la prensa alemana actual, surgida de la catarsis de 1945, no es ajena a la introducción de las TIC en el negocio periodístico, que ha supuesto un trasvase de lectores hacia las ediciones digitales de los medios.

Ese es el caso del Berliner Zeitung, periódico fundado en Berlín precisamente en 1945 y que se convirtió en el medio de mayor difusión en la República Democrática Alemana (RDA). Su importancia histórica se explica porque fue el primer diario creado en Alemania después la II Guerra Mundial. Tras la desaparición de la RDA en 1990, el Berliner Zeitung pasó por distintas manos privadas hasta acabar siendo propiedad de la editorial alemana M. DuMont Schauberg, sin conexiones importantes a priori con los grandes conglomerados de la información.

En el plano digital, el Berliner Zeitung demuestra una preocupación temprana por presentar sus informaciones en la red. La edición online data de otoño de 1994, fechas similares a la aparición del primer diario en Internet en España, con El Periódico de Catalunya (Salaverría, Martínez-Costa y Breiner, 2018). Sin embargo, sus informaciones siguen empleando en la actualidad géneros tradicionales. La consulta sistemática de su web durante tres meses permite comprobar que, de las fórmulas básicas de los géneros periodísticos en Internet (Salaverría, 2005), este cibermedio prescinde del párrafo de enganche y de la fragmentación hipertextual. Solo utiliza, y de forma muy básica, los elementos imprescindibles de Internet: título enlace, datación exhaustiva y enlaces documentales.

A ello se suma la ausencia de contenidos de redes sociales o vídeos en el cuerpo de las noticias. El audiovisual solo está presente en una galería web específica. Además, son fácilmente observables fórmulas como la falta de autoría o informaciones procedentes de agencias, prácticas identificadas con una baja calidad periodística (Handstein, 2010).

En cuanto al contenido, en el período de observación -julio a septiembre de 2018-, el Berliner Zeitung ha publicado 135 informaciones referidas a asuntos sobre la Unión Europea, lo que denota preocupación por la cuestión y, al menos, una cierta voluntad formal de "localizar" sobre temas globales. Sobre ello se profundizará en un caso concreto. Ese elevado número de publicaciones de la UE refleja que no es un cibermedio dedicado exclusivamente a los asuntos más locales.

Aunque la observación sistemática de sus publicaciones muestra ciertas lagunas, la variedad de temas y enfoques que desarrolla Berliner Zeitung hace que se le considere uno de los diarios más prestigiosos de Alemania, así como el medio más fuerte de los procedentes de la antigua RDA (Seidendorf, 2007; Handstein, 2010). La ciudad de Berlín cuenta con un importante pluralismo mediático: actualmente se editan 12 diarios, 8 de los cuales tienen enfoques locales. De todos ellos, los que tienen mayores tasas de suscripción son Tagesspiegel (nacional) y Berliner Zeitung (local). 
Según Seidendorf, el elevado número de suscritores continúa siendo la prueba por antonomasia de poseer un gran prestigio periodístico en el país germano (2007, p. 15).

\subsection{This is Local London}

Inglaterra es la cuna del liberalismo democrático y, por ende, el primer país del mundo en el que se configuró una opinión pública, con una prensa libre, ajustada a las exigencias del sistema democrático. Su tradición liberal explica que los ingleses sean grandes lectores de periódicos, con un elevado número de cabeceras. Asimismo, los periódicos británicos presentan unas características propias que los configuran como un sistema de medios único que apenas ha cambiado en los últimos cincuenta años. Existe una convivencia entre periódicos de élite "quality press" y populares, los famosos tabloides "tabloids", que tienen tiradas millonarias. Estos se caracterizan por un formato reducido, parecido al de una revista, y contenidos sensacionalistas.

This is Local London presenta rasgos de tabloide digital, con una web dotada de titulares impactantes y contenidos breves. Se trata de un medio nativo digital, nacido en 2001, y que pertenece a Newsquest Media Group, una de las editoriales más grandes de Reino Unido dedicada a la producción de contenidos periodísticos locales y regionales. Este grupo posee conexiones internacionales, ya que su empresa matriz es la estadounidense Gannett Company, dueña del USA Today.

En el plano digital, se trata de un medio nativo que no emplea géneros especialmente novedosos, dando uso a fórmulas básicas del ciberperiodismo. En la observación se aprecia una utilización sistemática del título enlace y el párrafo de enganche, así como una alta frecuencia de la fragmentación textual y los enlaces documentales. En cambio, This is Local London prescinde en todas sus informaciones de la datación exhaustiva, uno de los rasgos definitorios del periodismo en Internet.

La presencia de contenidos de redes sociales o vídeos en el cuerpo de las informaciones se produce en 63 de las informaciones analizadas. Hay que tener en cuenta que, de los 99 textos registrados, 77 se construyen a partir de declaraciones de protagonistas. Estas intervenciones son ilustradas frecuentemente por este medio con capturas de tuits o formatos audiovisuales.

En cuanto al contenido, este cibermedio ha publicado un total de 99 informaciones durante los tres meses de observación. De ellas, solo 2 no aludían al Brexit, el tema europeo por excelencia en Reino Unido desde el referéndum en 2016 que, en realidad, imbrica con las cuestiones nacionales y locales porque tiene una afectación directa en la ciudadanía. El enfoque predominante se perfila como bastante "localizado", en consonancia con el nombre del propio medio, This is Local London. No obstante, esta perspectiva no se vincula con la autoría, ya que todos los textos estudiados carecen de la firma del periodista; esta solo se realiza en los géneros opinativos.

\subsection{Sevilla Actualidad}

En España, la prensa arrastra un atraso histórico, motivado por la implantación tardía del liberalismo en el siglo XIX y la existencia de una dictadura durante buena parte del siglo XX. Esta situación provoca que los diarios españoles presenten bajos índices de lectura, careciendo del arraigo que se experimenta en otros países europeos; la salvedad la constituyen los periódicos de ámbito local, existiendo uno en casi cada capital de provincia (López García, 2008).

Los periódicos españoles llevan a cabo todavía estrategias ideológicas propias de la prensa de opinión decimonónica. Sin embargo, en el plano de Internet sí que existe una cierta pluralidad de 
medios y formatos desde los inicios de la Red (Almiron Roig, 2006). En este contexto se enmarca Sevilla Actualidad, un medio nativo digital con noticias para la ciudad de Sevilla creado en 2009 por los periodistas Christopher Rivas y Francisco Salvador. Este cibermedio pertenece al grupo Maravedismo, un proyecto dirigido por profesionales del sector de la comunicación y que cuenta con distintas iniciativas informativas en la provincia sevillana.

Sevilla Actualidad desarrolla una política de presencia constante en redes sociales (Facebook y Twitter) que, sin embargo, no se ve acompañada de formatos novedosos en su web. De las fórmulas definidas como propias del periodismo en Internet, este medio solo emplea el título enlace, la datación exhaustiva y los enlaces documentales. Además, un elevado número de textos no presenta autoría -en las noticias observadas sobre la UE no hay ninguno que lo haga- y la combinación con vídeos y publicaciones de redes sociales no ha sido apreciada en el período investigado.

Por otro lado, este cibermedio sí que desarrolla un original sistema para exponer datos de interés al lector. En la parte izquierda de la información sitúa un espacio que contiene el nombre y perfil de Twitter del autor (en caso de que la noticia vaya firmada), la datación exhaustiva, la posibilidad de escribir comentarios, el tiempo estimado de lectura y una herramienta para compartir en redes sociales. Este conjunto funciona como un elemento fijo que se mantiene a pesar de hacer "scroll" en la información.

En lo referente al contenido de las informaciones, Sevilla Actualidad cuenta con solo 16 informaciones acerca de la Unión Europea en el tiempo analizado. El sistema de propiedad de este cibermedio ya demostraba su elevada vinculación local. A continuación, se reflexionará con un caso práctico sobre el grado de "localización" de la información.

\subsection{Estudio comparativo ante el cambio de hora europeo}

El 4 de julio de 2018 la Comisión Europea lanzó una consulta pública -dirigida a la ciudadanía europea, las partes interesadas y los Estados miembros- con el objetivo de reflexionar acerca de la necesidad de modificar la Directiva de la UE sobre la hora de verano. Así lo había solicitado el Parlamento Europeo en una resolución de febrero de 2018. El actual texto legislativo, que data del año 2000, supone el cambio de hora dos veces al año para un mejor aprovechamiento de la luz diurna.

La consulta, cuyo plazo terminó el 16 de agosto de 2018, contó con la participación de 4,6 millones de europeos, tres veces más de lo habitual en estas iniciativas. El 30 de agosto el diario alemán Westfalenpost filtró los resultados y, al día siguiente, el presidente de la Comisión Europea, JeanClaude Juncker, los anunció de manera pública, algo también insólito.

El $80 \%$ de los participantes abogaba por suprimir el cambio de hora, una noticia que rápidamente tuvo un eco masivo en los medios europeos. Berliner Zeitung, This is Local London y Sevilla Actualidad publicaron informaciones al respecto, pero con distintos enfoques de periodismo local que pretendemos analizar.

Bajo el ilustrativo título "La hora del cambio de hora llega a su fin" ("Die Zeit für die Zeitumstellung läuft $a b$ "), este cibermedio publica una extensa noticia de 11 párrafos firmada por la Dpa (Agencia alemana de prensa). Se trata de un texto más propio de la prensa en papel, tanto por su tamaño como por su falta de herramientas digitales. Solo se emplea el título enlace y la datación exhaustiva, prescindiendo de los enlaces documentales que se habían registrado como habituales en este medio durante la fase de observación. 
El tratamiento de la información no contiene ningún elemento que permita caracterizarlo como periodismo local. No se contextualiza el hecho, a la vez que no hay información sobre la dimensión que la noticia tiene para los habitantes de la ciudad o de la región. El extenso texto se construye con declaraciones de políticos alemanes a nivel nacional, sin mencionar ámbitos públicos de proximidad. La noticia también da cuenta de la tasa de participación en distintos países europeos, pero no de cómo se reparte la misma en los Estados de Alemania, lo que hubiese sido de interés para conocer la expectación que esta consulta despertó en el Estado de Berlín.

La noticia de Berliner Zeitung está elaborada por una agencia, algo que se puede deducir también de la información publicada al respecto por Sevilla Actualidad, titulada "Bruselas debate si suprimir el cambio de hora, como pide una mayoría de europeos". Aunque no viene firmada, su contenido se basa en declaraciones en rueda de prensa del portavoz de Comisión Europea, Margaritis Schinas, por lo que difícilmente se trata de datos que el cibermedio haya obtenido de forma directa, y sí a través de teletipos. Además, ese mismo título fue empleado por el diario $A B C$ en una información publicada en esa fecha, evidenciando aún más su origen común de agencia.

Sevilla Actualidad elabora un texto sobre el cambio de hora también propio de la prensa impresa, con el título enlace y la datación exhaustiva como únicas prácticas ciberperiodísticas. Su información tampoco presenta referencias locales, ni de sus implicaciones ni a nivel político. En esto coinciden Sevilla Actualidad y Berliner Zeitung; su diferencia radica en que el enfoque del cibermedio sevillano es europeo, girando su noticia en torno a las declaraciones de un portavoz comunitario, mientras que en el diario alemán su planteamiento es nacional, ya que se construye con intervenciones de políticos germanos de elevado rango, así como con valoraciones sobre el distinto grado de participación por países.

This is Local London desarrolla una práctica más singular y más próxima al concepto de "localización" que viene exponiendo este artículo. Este cibermedio publica una información titulada "¿Cuándo cambian los relojes?" (“When do the clocks change?"), firmada por una periodista y que aborda tanto el momento en que tiene lugar el próximo cambio horario como las implicaciones de este para la salud. Asimismo, confecciona un decálogo de recomendaciones para combatir los efectos perjudiciales de la modificación horaria, en lo que supone un claro ejemplo de información de servicio.

A pesar de que, con el Brexit, Reino Unido dejaría de estar sometido a las decisiones horarias de la Comisión Europea, el medio británico "localiza" con su enfoque la información sobre el cambio de hora, entendiéndola y presentándola desde parámetros de proximidad. No obstante, su utilización de fórmulas digitales es muy escasa, explotando únicamente el título enlace y el párrafo enganche. Al igual que en los otros diarios analizados, resulta llamativa la ausencia de enlaces documentales, tan característicos del periodismo en Internet.

El análisis comparado del tratamiento de la posible supresión del horario veraniego arroja datos diferentes en el enfoque, pero similares en el plano digital. Se han tomado como estudio de casos las informaciones publicadas como respuesta a esta propuesta por tres cibermedios. Berliner Zeitung y Sevilla Actualidad desarrollan un planteamiento nacional e internacional, respectivamente, alejado por completo de perspectivas de la importancia del hecho a escala local. Ambas publican textos que se adscriben a la noticia como género. Por su parte, This is Local London produce un reportaje breve, pero centrado en las repercusiones que las modificaciones horarias tienen en la vida de los ciudadanos londinenses.

Este estudio comparativo también revela la pobreza de sus estrategias digitales. Dos de los tres medios analizados -This is Local London y Sevilla Actualidad-son nativos digitales, mientras que el 
otro -Berliner Zeitung- es pionero en esta materia, dado que inició su publicación online en 1994. Sin embargo, los tres cibermedios presentan informaciones compuestas exclusivamente por texto $\mathrm{y}$ fotografía, fácilmente homologables con las de los periódicos tradicionales.

El cambio horario supone una cuestión del día a día que puede modificar los usos y costumbres de la población de las ciudades estudiadas. Por ello, que un tema de estas características no merezca fórmulas digitales de calidad resulta preocupante, como también lo es que dos de los cibermedios analizados presenten simplemente una copia y pega de agencia en su información central sobre el tema.

\section{Análisis de resultados}

\subsection{Características de los cibermedios locales analizados}

En el marco de nuestro estudio de casos, se observa un denominador común de superficialidad en el tratamiento de aspectos a priori lejanos, como las decisiones de la UE, pero que, en el caso del cambio de hora, tienen una repercusión directa en la vida de los ciudadanos. Esta escasa calidad es mayor en Berliner Zeitung y Sevilla Actualidad, donde la información procede de agencias que no están debidamente referenciadas en la autoría.

La falta de profundidad se plasma en enfoques alejados de la "localización", que producen la información desde perspectivas nacionales e internacionales. Solo This is Local London desarrolla un reportaje que detalla cómo combatir los efectos adversos del cambio de hora. Puesto que todos los cibermedios seleccionados se encuentran por definición vinculados a una ciudad, no siendo ni hiperlocales ni regionales, esta carencia mayoritaria de rasgos del periodismo local se muestra como contradictoria.

Por otra parte, como se ha visto los tres medios seleccionados poseen una estrecha relación con Internet. Sin embargo, son digitales solo en su continente, pero no en contenido. La capacidad democratizadora atribuida a los cibermedios de proximidad (López García, 2008), motivada por su capacidad de servir como flujo de informaciones independientes en formatos múltiples, se ve en este caso mermada por la no explotación de todas sus potencialidades comunicativas.

La comunicación local aglutina cuatro características diferenciadoras: proximidad, mayor interactividad, función de servicio y lenguaje directo (Esteve Ramírez, 2002). Únicamente This is Local London combina la proximidad, la función de servicio y el lenguaje directo; los otros dos cibermedios adolecen de cualquiera de estos rasgos en la información común analizada. Especialmente significativa es la situación de la interactividad, que se encuentra totalmente anulada en los tres diarios online por la inexistencia de fórmulas digitales de calidad. Por su parte, la proximidad se ve comprometida por la falta de profesionalidad que entraña el uso único de agencias en el cibermedio berlinés y el sevillano.

El desarrollo tecnológico ha supuesto la aparición de nuevos lenguajes digitales y necesidades informativas que revitalizan el interés por lo próximo (López García et al., 2015). Sin embargo, estas necesidades no se hallan satisfechas en un tema de máxima actualidad en Berliner Zeitung y Sevilla Actualidad, cibermedios locales de importantes ciudades europeas. Berliner Zeitung pertenece a un conglomerado de medios tradicional, pero Sevilla Actualidad se vincula con las nuevas empresas nativas digitales dirigidas por periodistas.

La crisis de la prensa local tradicional ha supuesto la emergencia de un periodismo de proximidad hiperlocal, estructurado en torno a cooperativas que siguen los postulados de la Economía Social. 
Este sistema permite satisfacer mejor las necesidades de los ciudadanos (Melián Navarro y Campos Climent, 2010). Si bien Sevilla Actualidad no es una cooperativa, su empresa matriz está conformada exclusivamente por periodistas que buscan que el medio proporcione un tratamiento informativo acorde a las demandas de la población. Además, cuenta con una cobertura por barrios que lo acerca al hiperlocalismo, área que ha sido conceptualizada como más "democratizadora" (López-García, Negreira-Rey y Rodríguez-Vázquez, 2016, p. 229).

Tanto los medios nativos digitales -This is Local London y Sevilla Actualidad- como los que proceden de una edición en papel se topan con la dificultad de rentabilizar sus inversiones, algo que no se ha resuelto en estos años de auge del periodismo digital. Por el momento no es viable el modelo de un diario digital cuya única fuente de ingresos es la publicidad, ya que "sería necesario que tuviese de 800 a 1000 millones de páginas vistas por mes para conseguir 56 millones de euros al año de publicidad" (Martínez Molina, 2010, p. 142). El gran desarrollo de los smartphones en los últimos años evidencia que las formas de consumo en el mundo digital son muy volátiles, dificultando aún más el reto de monetizar los contenidos.

No hay que perder de vista la importancia que tiene la Estructura de la Información para contextualizar las deficientes prácticas periodísticas. En el marco de la economía política de la comunicación, la actual globalización y precarización del sector mediático ha tenido especiales repercusiones en los medios locales, debido a su menor tamaño (González Esteban, 2009). Esto implica una imposibilidad económica de mantener a corresponsales en Bruselas, pero también dificultades en cuanto a recursos humanos para ofrecer una información de calidad desde la redacción. Los escasos ingresos procedentes del ámbito digital no alcanzan todavía para paliar estos problemas.

En el actual contexto digital, el otrora poder exclusivo de los mass-media como único intermediario se diluye, dando paso a la cada vez más importante marca del periodista (López-Meri y CaseroRipollés, 2017). El autor de la información resulta cada vez más reconocible gracias a su presencia en redes sociales, por lo que debe granjearse un prestigio en su relación con el público para lograr un mayor alcance de sus informaciones. En la prensa local, la proximidad asociada a esta área de especialización periodística provoca que la función de la marca del periodista debiera ser aún mayor, algo que no ocurre en los textos analizados Berliner Zeitung y Sevilla Actualidad, ya que no se firman las informaciones.

Mucho se ha reflexionado sobre la supuesta capacidad de los cibermedios para hacer sentir al lector como parte deliberativa e integrante de la comunidad. Desde un punto de vista teórico, las nuevas tecnologías digitales poseen grandes ventajas para ambas partes -medios y receptores-, al tener la capacidad de servir de catalizadores de demandas de los lectores que habían sido ignoradas hasta ahora (Karlsson, Clerwall y Nord, 2018, p. 578). No obstante, desde la literatura académica también se incide en que esta dinámica no está provocada en sí por Internet, sino por una variación en la concepción del periodismo, visto hoy en día desde una óptica mucho más participativa (Loosen y Schmidt, 2012; Borger, Van Hoof y Sanders, 2016).

Asimismo, se halla en discusión que el grado de participación del periodismo digital sea tan democratizador y positivo como el que muestra la representación discursiva de los medios (GarcíaOrosa, 2018). El caso aquí analizado es prueba de que los cibermedios no implican necesariamente fórmulas más participativas y, por tanto, no aseguran un mayor cumplimiento del "contrato social", teoría que en periodismo parte de la premisa de que la prensa cumple la función social referida a difundir las demandas de la ciudadanía (Merrill, 2011; Karlsson, Clerwal y Nord, 2018), a la vez que sirve de plataforma para dar a conocer las actuaciones del poder público. 
Los tres medios estudiados tienen cuentas de Facebook y Twitter. Berliner Zeitung y This is Local London incorporan además número de WhatsApp. La utilización de esta aplicación móvil de uso diario refleja una voluntad de mantener un contacto personal con el lector, aprovechando para ello la tecnología "smartphone". El valor de los lazos interpersonales es clave en la configuración de la información que recibimos a través de Internet (McCollough, Crowell y Napoli, 2016). Esta vertiente humana es mayor si cabe en la prensa local, por su pertenencia al ámbito de la proximidad, una conciencia que, al menos formalmente, muestran los medios analizados con su presencia en redes sociales.

\subsection{Conceptualización de un periodismo "localizado" a escala europea}

Como hemos visto, el periodismo local posee una serie de peculiaridades que lo convierten en una especialización periodística. Estos rasgos provienen de su contacto más directo con la audiencia, lo que acaba generando un mayor compromiso con la misma. En una definición clásica, Gomis señalaba que "las noticias locales son el tejido de la democracia" (1974, p. 127), puesto que son estas informaciones las que estrechan lazos de los ciudadanos con sus vecinos y representante políticos más cercanos, construyendo un sentimiento de comunidad.

Tradicionalmente, la información local es considerada como aquella que recoge los acontecimientos producidos en una determinada zona y afectan a su política, urbanismo, ecología, costumbres y realidad socio-cultural (Esteve Ramírez y Fernández del Moral, 2009, p. 79). Mediante esta noción los autores se refieren a la proximidad geográfica como primer elemento objetivo de interés periodístico. Frente a ello, en este artículo hemos apostado por conceptualizar un periodismo "localizado", que no se define por abordar temas próximos, sino por enfocar la realidad desde unas "gafas locales", lo que implica observar los hechos globales con unos parámetros propios según el territorio.

Nuestro planteamiento es que lo local supone un criterio periodístico más temático que geográfico, al contrario de lo que se ha valorado habitualmente. Somos críticos con la posición que argumenta que ya no se puede hablar de información local, puesto que cualquier texto es susceptible de tener repercusión masiva (Franklin, 2006). Es cierto que la velocidad de difusión de las nuevas tecnologías ha convertido a la prensa local en un elemento más de la información globalizada. Sin embargo, son varios los autores que, como Izquierdo Labella (2010), Möhring (2015) o Leupold, Klinger y Jarren (2018), coinciden en que los diarios locales siguen jugando un papel fundamental en la construcción del sentimiento de comunidad.

La información "localizada" sería aquella que trata periodísticamente los hechos internacionales, nacionales, regionales y locales desde una perspectiva de proximidad. El foco cercano es el elemento diferencial a la hora de abordar una noticia, aplicando criterios de servicio público. Este tipo de información resulta competitiva en el sector por su bajo precio, ya que no es necesario tener un periodista destinado en Bruselas, como sería el caso de la Unión Europea, para elaborar una información de calidad. El texto analizado de This is Local London ejemplifica cómo se puede cubrir un suceso transnacional desde la perspectiva de lo que le importa al ciudadano local.

El nuevo público hiperconectado presenta necesidades a las que los cibermedios locales deben responder. Ante la obligación de hacer comprender fenómenos políticos complejos y postmaterialistas, la clave pasa por encajar una doble visión que el ser humano siempre ha compartido: la universalidad y la cercanía (De Fontcuberta, 1997, p. 48). En un contexto de lecturas informativas cada vez más cortas, la "localización" puede ser una respuesta que hibride ambas vertientes, exponiendo al lector de manera sucinta una información de máximo interés. 
Como se ha visto, la proximidad es un elemento central que ha estado presente desde los mismos orígenes del periodismo. Internet está dando cabida también a un enfoque hiperlocal, con una proliferación de publicaciones destinadas a satisfacer las demandas informativas de municipios e incluso barrios. De acuerdo a un estudio del Pew Research $\mathrm{Center}^{2}$, los medios hiperlocales suponían en 2015 más de la mitad de las iniciativas periodísticas digitales.

La proliferación de diarios hiperlocales en Internet, con sus consiguientes perfiles en redes sociales, no siempre se ajusta a criterios periodísticos (Williams, Harte y Turner, 2015). Frente a ellos se erigen los cibermedios locales con pretensiones de cobertura más amplias, herederos de una amplia trayectoria en papel en países como Alemania y España. No obstante, medios de estas características, como Berliner Zeitung y Sevilla Actualidad, emplean en el caso aquí estudiado a las agencias como fuentes únicas, en lo que supone una práctica periodística poco especializada (Pérez Curiel et al., 2015).

El periodismo "localizado" que proponemos debería rehuir de prácticas despersonalizadas, caso del uso único de agencias, pero también de enfoques excesivamente limitados propios de los medios hiperlocales. El objetivo es proporcionar una información con aspiraciones de ser completa para la compresión del mundo.

Uno de los factores determinantes para concebir a los medios locales como próximos frente a sus competidores es el rol activo de sus audiencias (Loosen y Schmidt, 2012). En ello desempeñan un papel central las redes sociales, posibilitando la actuación de los ciudadanos como fuentes de información. Esto explica el uso continuado que de las redes sociales han llevado a cabo los diarios locales desde los primeros momentos de esta tecnología.

Más allá de la presencia en redes sociales, los medios "localizados" online deberían aprovechar todas las potencialidades expresivas del ciberperiodismo. Ya no solamente hablamos de la fragmentación hipertextual o los enlaces documentales (Salaverría, 2005) estrategias clásicas en esta área, sino de nuevas fórmulas que permiten presentar informaciones de una manera más participativa y amena, como las narrativas transmedia (Scolari, 2009).

Estas innovaciones serían empleadas para elaborar una información local que, siguiendo la definición de la profesora María Pilar Diezhandino, potencie "todo aquello que, sin ser estrictamente noticia, puede tener utilidad inmediata para el receptor" (López García y Maciá Mercadé. 2007, p. 14). Este enfoque utilitarista coincide con el propio de redes sociales como Twitter, que buscan generar de forma inmediata una información de interés para el lector. En consecuencia, la simbiosis entre información local y redes sociales debe ser aprovechada por el periodismo "localizado" para contribuir a generar un contenido relevante que haga posible valorar la realidad desde un enfoque de proximidad.

\section{Discusión y conclusiones}

El presente artículo ahonda en la posibilidad de innovar en los contenidos periodísticos locales con el objetivo de aportar valor a los ciudadanos construyendo comunidad (Novy, Swiatek y Moulaert, 2012; Nielsen, 2015). Con esta finalidad, nuestra propuesta aboga por desarrollar un periodismo "localizado" digital, cuyo enfoque constituye el factor diferenciador ante otras áreas de especialización periodística. Esta postura rechaza las aproximaciones de autores como Franklin (2006) y Hume (2012), que consideran que la información local ha desaparecido debido a que, en la actualidad, cualquier hecho puede alcanzar una repercusión global.

${ }^{2}$ Local News in a Digital Age (2015). Accesible en http://www.journalism.org/2015/03/05/local-news-in-a-digital-age/ 
El estudio de casos muestra un ejemplo de cómo se puede innovar en el contenido tomando como referencia una información de interés y de servicio público a partir de una noticia de la Unión Europea, tal y como observamos en la información analizada de This is Local London. Este medio y Berliner Zeitung se caracterizan por combinar la información de proximidad con un periodismo de escala global, dando cabida a asuntos de temática internacional, algo que no se experimenta en el cibermedio español estudiado, que apenas concede espacio a estos asuntos.

El principal problema de las noticias estudiadas en Berliner Zeitung y Sevilla Actualidad es que se construyen a través de agencias, hasta el punto de que son homologables con el texto publicado por otros medios. Además, no hay ningún elemento periodístico que permita identificarlas con información local, sino que se fundamentan únicamente en las declaraciones de un protagonista internacional. El cibermedio de dimensión "local" acaba convertido en el simple transmisor de un contenido genérico con nulo valor añadido para su audiencia segmentada geográficamente.

Otro aspecto preocupante, observado en los tres medios, es que sus informaciones presentan fórmulas de la prensa en papel en un marco de periodismo online. Los cibermedios locales suelen tener pocos recursos económicos (Lauterer, 2006), pero esto no es óbice para cumplir el mínimo de hipertextualidad que requiere la información en la Red. Más allá del lenguaje digital, el texto estudiado de This is Local London evidencia que es posible realizar una información local barata y de calidad, simplemente con cumplir con la función de servicio público de dar a conocer lo que implica una decisión política.

La prensa local europea no es ajena a los procesos de concentración mediática que se experimentan a nivel mundial. Sin embargo, en la prensa local tradicional de varios países perviven todavía grupos de naturaleza regional sin vinculaciones externas, algo que observamos en Berliner Zeitung y Sevilla Actualidad. Esto significa a priori una mayor independencia y, por ende, una elevada capacidad formal de desarrollar un periodismo más innovador, libre de ataduras y comprometido con sus lectores.

La revisión crítica de la literatura efectuada, así como lo recopilado en el estudio de casos, nos llevan a exponer un decálogo sobre la innovación en el periodismo "localizado" en el contexto digital. Se trata de una serie de recomendaciones no exhaustivas que pretenden servir como guía para una información local de mayor calidad orientada a generar valor añadido a la ciudadanía:

1. La perspectiva local como prisma para observar el mundo: la realidad es presentada desde los parámetros de la comunidad que recibe la información. Esto significa que se tienen en cuenta las costumbres y sensibilidades del público, así como sus necesidades informativas. Se trata en definitiva de un cambio estratégico en la misión de la empresa y en la actitud de sus directivos y trabajadores, el tránsito de una orientación al producto a una orientación a las necesidades informativas de los lectores locales. Los medios deben convertirse en expertos conocedores de las necesidades informativas y del comportamiento de consumo de su público local, en aras de ofrecer la información que necesita en el formato y momento en que la necesita.

2. Noticias propias como máxima: la información de agencia es útil como fuente, pero no puede constituir la base de la noticia. Se sugiere innovar en contenido. La diferenciación del servicio informativo debe estar basada en aportar al público local lo que otros medios no pueden aportan. A pesar de que el hecho noticioso suceda a miles de kilómetros de distancia, el periodista debe adaptarlo aplicando su conocimiento detallado de la comunidad local en la que desarrolla su trabajo.

3. Información de carácter divulgativo: el texto informativo está elaborado de forma que sea comprensible para el público lego que conforma una sociedad local. Esta comprensibilidad 
radica en el hecho de que el receptor sea capaz de entender las causas y consecuencias del hecho a partir de la lectura de la noticia, lo que permitiría a la información local cumplir su función social de construir democracia a escala de proximidad (Gomis 1974, Möhring 2015).

4. Ciberperiodismo de calidad adaptado al ámbito digital: las noticias en estos medios en Red deben cumplir, al menos, las tres características propias del ciberperiodismo: hipertextualidad, multimedialidad e interactividad (García de Torres y Pou Amérigo, 2003). A ellas se suman el empleo de las técnicas básicas de los géneros periodísticos en Internet, que son título enlace, datación exhaustiva, fragmentación hipertextual, párrafo de enganche y enlaces documentales (Salaverría, 2005). El uso de todas estas fórmulas constituye el denominador común de una información de calidad en Internet. En la actualidad, y en aras de elaborar productos periodísticos de mayor impacto y accesibilidad, aparecen narrativas transmedia (Scolari, 2009), entre las que se encuentran géneros como la gamificación (García-Ortega y García-Avilés, 2018).

5. Información de bajo coste productivo: si bien el uso de nuevos formatos como el transmedia puede incrementar el coste de producir la información -los freelances expertos en esta tecnología suponen una buena opción (Serrano Tellería, 2016)-, crear contenidos en Red que cumplan los requisitos mínimos del ciberperiodismo resulta económicamente accesible. Existen plataformas de software libre y servidores gratuitos que abaratan hacer periodismo online. Además, para "localizar" noticias no es necesario tener destinados a periodistas en lugares lejanos, como ha evidenciado en este artículo This is Local London, sino contar en plantilla con profesionales que posean un profundo conocimiento tanto de la realidad local como de aquellos aspectos regionales, nacionales o internacionales que puedan intervenir en ella. La innovación en procesos se antoja clave para la supervivencia de los medios locales.

Hay asuntos, como la supresión del cambio de hora propuesta por la Comisión Europea, que reflejan por su trascendencia la pertinencia de que los medios locales contextualicen e informen sobre las repercusiones de la noticia al ciudadano de a pie, es decir, que "localicen" la información. Más allá de algunos comentarios apocalípticos sobre la calidad del periodismo de proximidad, son muchos los académicos y periodistas que valoran la significación de la prensa como cronista de las comunidades locales en el universo de Internet (Hastjarjo, 2017, p. 21). Se reconoce así la función democrática de los cibermedios locales, tanto por su rol de presentar informaciones independientes como por ser comentarista de los temas, no más próximos, sino que más afectan al ciudadano en el caso del periodismo "localizado".

\section{Referencias bibliográficas}

Almiron Roig, N. (2006). Los valores del periodismo en la convergencia digital: civic journalism y quinto poder. Revista Latina de Comunicación Social, 61, 1-12.

Alonso-Muñoz, L. y Casero-Ripollés, A. (2017). Transparencia y monitorización en el entorno digital. Hacia una tipología de las plataformas impulsadas por la ciudadanía. Revista Latina de Comunicación Social, 72, 1.351-1.366. https://doi.org/10.4185/RLCS-2017-1223

Armentia Vizuete, J. I. y Caminos Marcet, J.M. (2003). Fundamentos de periodismo impreso. Ariel.

Barnett, S. \& Townend, J. (2015). Plurality, Policy and the Local. Journalism Practice, 9(3), 332349. https://doi.org/10.1080/17512786.2014.943930

Bel Mallén, I. (2002). La información local en la Comunidad Autónoma de Madrid. Fundación de la Comunicación Social, D.L. 
Berganza Conde, M. R. (2000). Comunicación, opinión pública y prensa en la sociología de Robert E. Park. CIS, Siglo XXI de España.

Berliner Zeitung (2018). Die Zeit für die Zeitumstellung läuft ab. https://www.berlinerzeitung.de/politik/die-zeit-fuer-die-zeitumstellung-laeuft-ab-31194586

Boczkowski, P. J. \& De Santos, M. (2007). When More Media Equals Less News: Patterns of Content Homogenization in Argentina's Leading Print and Online Newspapers. Political Communication, 24(2), 167-180, https://doi.org/10.1080/10584600701313025

Borger, M., Van Hoof, A. \& Sanders, J. (2016). Exploring participatory journalistic content: Objectivity and diversity in five examples of participatory journalism. Journalism, 1-23. https://doi.org/10.1177/1464884916675633

Byerly, K. R. (1961). Community Journalism. Chilton.

Carson, A., Muller, D., Martin, J. \& Simons, M. (2016). A new symbiosis? Opportunities and challenges to hyperlocal journalism in the digital age. Media International Australia, 161(1), 132146. https://doi.org/10.1177/1329878X16648390

Codina, L., Pedraza, R., Díaz Noci, J., Rodríguez-Martínez, R., Pérez-Montoro, M. y CavallerReyes, V. (2014). Sistema Articulado de Análisis de Cibermedios (SAAC). Una propuesta sobre el qué y el cómo para estudiar medios de comunicación digitales. Hipertext.net [online], 12.

Costa Sánchez, C. (2012). Ciberperiodismo en el smartphone. Estudio de la multimedialidad, usabilidad, hipertextualidad e interactividad de las aplicaciones de medios nativos digitales para smartphone. Estudios sobre el mensaje periodístico, 18(1), 243-251.

De Fontcuberta, M. M. (1997). La identidad regional de los medios. Cuadernos de información, 12, 44-50. https://doi.org/10.7764/cdi.12.207

Diezhandino, M. P. (1994). Periodismo de servicio: la utilidad como complemento informativo en Time, Newsweek y U. S. News and World Report, y unos apuntes del caso español. Bosch.

Esteve Ramírez, F. (2002). La información local como área de especialización periodística. En R. López Lita, F. Fernández Beltrán y A. Durán Mañés (Eds.). La prensa local y la prensa gratuita (pp. 483-492). Publicacions de la Universitat Jaume I.

Esteve Ramírez, F. y Fernández del Moral, J. (2009). Áreas de especialización periodística. Fragua.

Firmstone, J., \& Coleman, S. (2014). The Changing Role of the Local News Media in Enabling Citizens to Engage in Local Democracies. Journalism Practice, 8(5), 596-606. https://doi.org/10.1080/17512786.2014.895516

Franklin, B. (2006). Local journalism and local media: making the local news. Routledge.

Gainous, J. \& Wagner, K. M. (2013). The Social Media Revolution in American Politics. Oxford University Press. 
García Avilés, J. A. \& Carvajal, M. (2008). Integrated and Cross-Media Newsroom convergence: two models of multimedia news production: The Cases of Novotécnica and La Verdad Multimedia in Spain. Convergence, 14(2), 223-241.

García de Torres, E. y Pou Amérigo, M. (2003). Características de la comunicación digital. En: Díaz Noci, J. y Salaverría, R. (Coords.), Manual de redacción ciberperiodística, (pp. 49-79). Ariel.

García-Orosa, B. (2018). Perfil de la audiencia de cibermedios: representación discursiva y praxis del receptor 2.0. Palabra Clave, 21(1), 111-133. https://doi.org/10.5294/pacla.2018.21.1.6

García-Ortega, A. y García-Avilés, J. A. (2018). Los newsgames como estrategia narrativa en el periodismo transmedia: propuesta de un modelo de análisis. Revista Mediterránea de Comunicación/Mediterranean Journal of Communication, 9(1), 327-346. https://doi.org/10.14198/MEDCOM2018.9.1.19

Gómez-Diago, G. (2010). Triangulación metodológica: Paradigma para investigar desde la ciencia de la comunicación. Razón y palabra, 72. http://www.razonypalabra.org.mx/N/N72/Varia_72/4_Gomez_Diago_72.pdf

Gomis, L. (1974). El medio media: la función política de la prensa. Seminarios y Ediciones.

González Esteban, J. L. (2009). Modelos de periodismo local y estrategias ante la crisis: el caso del News \& Observer. Revista Latina de Comunicación Social, 64, 151-160. https://doi.org/10.4185/RLCS-64-2009-813-151-160

Handstein, H. (2010). Qualität im lokalen Zeitungsjournalismus. Theoretischer Entwurf und empirische Fallstudie. AVM Akademische Verlagsgemeinschaft.

Hastjarjo, S. (2017). Local Journalism in the New Media Landscape: Opportunities and Challenges. The International Conference on Design and Technology, $\mathrm{KnE}$ Social Sciences, 21-27. https://doi.org/10.18502/kss.v2i4.863

Hess, K. \& Waller, L. (2016). River flows and profit flows. Journalism Studies, 17(3), 263-276. https://doi.org/10.1080/1461670X.2014.981099

Hume, J. (2012). Community Journalism and Community History. En Reader, B. y Hatcher, J. (Eds.), Foundations of Community Journalism, (pp. 65-82). Sage.

Ihlebæk, K. A. \& Krumsvik, A. H. (2015). Editorial power and public participation in online newspapers. Journalism, 16(4), 470-487.

Izquierdo Labella, L. (2010). Manual de periodismo local. Fragua.

Karlsson, M., Clerwall, C. \& Nord, L. (2018). The public doesn't miss the public. Views from the people: Why news by the people? Journalism, 19(5), 577-594.

https://doi.org/10.1177/1464884917694399

Lauterer, J. (2006). Community journalism: relentlessly local. University of North Carolina Press. 
Leupold, A., Klinger, U. \& Jarren, O. (2018). Imagining the City. Journalism Studies, 19(7), 960982. https://doi.org/10.1080/1461670X.2016.1245111

Lewis, S. C., Kaufhold, K. \& Lasorsa, D. L. (2010). Thinking about Citizen Journalism. Journalism Practice, 4(2), 163-179. https://doi.org/10.1080/14616700903156919

Loosen, W. \& Schmidt, J. H. (2012). (Re-) Discovering the audience. Information, Communication \& Society, 15(6), 867-887. https://doi.org/10.1080/1369118X.2012.665467

López García, G. (2015). Periodismo digital. Redes, audiencias y modelos de negocio. Comunicación Social Ediciones y Publicaciones.

López García, X. y Maciá Mercadé, J. (2007). Periodismo de proximidad. Editorial Síntesis.

López García, X. (2008). Ciberperiodismo en la proximidad. Comunicación Social ediciones y publicaciones.

López García, X., Toural Bran, C., Rodríguez Vázquez, A. I. y Silva Rodríguez, A. (2015). Cibermedios de proximidad en España y Portugal en las redes sociales: vías para estrechar vínculos en comunidades locales. Revista Latina de Comunicación Social, 70(7), 833-858.

López-García, X., Negreira-Rey, M. y Rodríguez-Vázquez, A. (2016). Cibermedios hiperlocales ibéricos: el nacimiento de una nueva red de proximidad. Cuadernos. Info, 39, 225-240. https://doi.org/10.7764/cdi.39.966

López-Meri, A. y Casero-Ripollés, A. (2017). Las estrategias de los periodistas para la construcción de marca personal en Twitter: posicionamiento, curación de contenidos, personalización y especialización. Revista Mediterránea de Comunicación/Mediterranean Journal of Communication, 8(1), 59-73.

Martínez Molina, M. (2010). En un escenario complejo de transformación. La crisis de los grandes periódicos. Revista Iberoamericana de Comunicación/Iberoamerican Communication Review, 2.

McCollough, K., Crowell, J. K. y Napoli P. M. (2016). Portrait of the Online Local News Audience. Digital Journalism. https://doi.org/10.1080/21670811.2016.1152160

McNair, B. (2004) [1999]. An Introduction to Political Communication (Communication and Society). Routledge.

McQuail, D. (2000) [1994]. McQuail's mass communication theory. Sage.

Melián Navarro, A. y Campos Climent, V. (2010). Emprendedurismo y economía social como mecanismos de inserción sociolaboral en tiempos de crisis. REVESCO: revista de estudios cooperativos, 100, 43-67.

Merrill, J. C. (2011). Journalism and democracy. En W. Lowrey y P. J. Gade (Eds.). Changing the news: the forces shaping journalism in uncertain times (pp. 45-62). Routledge.

Möhring, W. (2015). Lokaljournalismus im Fokus der Wissenschaft. Landesmedienanstalt Nordrhein-Westfalen. 
Napoli, P. M., Stonbely, S., McCollough, K. \& Renninger, B. (2017). Local Journalism and the Information Needs of Local Communities. Journalism Practice, 11(4), 373-395. https://doi.org/10.1080/17512786.2016.1146625

Nielsen, R. K. (2015). Local Newspapers as Keystone Media: The Increased Importance of Diminished Newspapers for Local Political Information Environments. En R. K. Nielsen (Ed.). Local Journalism: the decline of newspapers and the rise of digital media (pp. 51-72). I.B. Tauris.

Novy, A., Swiatek, D. N. y Moulaert, F. (2012). Social Cohesion: A Conceptual and Political Elucidation. Urban Studies, 49(9), 1873-1889. https://doi.org/10.1177/0042098012444878.

OCDE/Eurostat (2018). Oslo Manual 2018: Guidelines for Collecting, Reporting and Using Data on Innovation, 4th Edition. París; Luxemburgo: The Measurement of Scientific, Technological and Innovation Activities, OECD.

Park, R. E., Burgess, E. W. \& McKenzie, R. D. (1974). The city. Chicago: The University of Chicago Press.

Pérez Curiel, C., Gutiérrez Rubio, D., Sánchez González, T. y Zurbano Berenguer, B. (2015). El uso de fuentes periodísticas en las secciones de Política, Economía y Cultura en el Periodismo de Proximidad Español. Estudios sobre el Mensaje Periodístico, 21 (Especial noviembre "Periodismo e información de calidad"), 101-117. https://doi.org/10.5209/rev ESMP.2015.v21.50661

Robinson, S. (2014). Introduction: Community journalism midst media revolution. Journalism Practice, 8(2), 113-120. https://doi.org/10.1080/17512786.2013.859822

Rodríguez Rey, A., Enguix González, A., Rojas Torrijos, J. L. y García Gordillo, M. M. (2015). La calidad de los medios y el uso de fuentes periodísticas en la prensa local de referencia en España. Estudios sobre el Mensaje Periodístico, 21 (Especial noviembre "Periodismo e información de calidad"), 85-100. https://doi.org/10.5209/rev ESMP.2015.v21.50659

Salaverría, R. (2005). Redacción periodística en Internet. Eunsa.

Salaverría, R.; Martínez-Costa M.P y Breiner, J. (2018). Mapa de los cibermedios de España en 2018: análisis cuantitativo. Revista Latina de Comunicación Social, 73, 1034-1053. https://doi.org/10.4185/RLCS-2018-1295

Sevilla Actualidad (2018). Bruselas debate si suprimir cambio de hora, como pide una mayoría de europeos. http://www.sevillaactualidad.com/mas-actualidad/103702-bruselas-debate-si-suprimircambio-de-hora-como-pide-una-mayoria-de-europeos/

Schudson, M. (2008). Why democracies need an unlovable press. Polity.

Scolari, C. (2009). Transmedia Storytelling: Implicit Consumers, Narrative Worlds, and Branding in Contemporary Media Production. International Journal of Communication, 3, 586-606.

Seidendorf, S. (2007). Europäisierung nationaler Identitätsdiskurse?: ein Vergleich französischer und deutscher Printmedien. Nomos. 
Serrano Tellería, A. (2016). Transmedia Journalism: Exploring Genres and Interface Design. Trípodos, 38, 67-85.

Slater, A. (2018). When do the clocks change?

https://www.thisislocallondon.co.uk/news/16903929.when-do-the-clocks-change

Welbers, K., Van Atteveldt, W., Kleinnijenhuis, J. \& Ruigrok, N. (2018). A Gatekeeper among Gatekeepers, Journalism Studies, 19(3), 315-333.

https://doi.org/10.1080/1461670X.2016.1190663

Williams, A., Harte, D. \& Turner, J. (2015). The Value of UK Hyperlocal Community News. Digital Journalism, 3(5), 680-703. https://doi.org/10.1080/21670811.2014.965932

Yunquera Nieto, J. (2016). Revistas y diarios digitales en España: historia de una evolución. Editorial UOC.

\section{AUTORES:}

\section{Rubén Rivas-de-Roca}

Departamento de Periodismo II. Facultad de Comunicación. Universidad de Sevilla. España.

Rubén Rivas de Roca es Personal Investigador en Formación (PIF) del Departamento de Periodismo II de la Universidad de Sevilla. Doctorando en Comunicación (línea Periodismo) del programa interuniversitario de las universidades de Cádiz, Huelva, Málaga y Sevilla. Graduado en Periodismo (Premio Extraordinario Fin de Estudios y Premio Nacional Fin de Carrera 2014-2015) y Máster Universitario en Estudios Europeos (Premio Extraordinario Fin de Estudios) por la Universidad de Sevilla. Además, en estos momentos también cursa el Máster Universitario en Comunicación, Cultura, Sociedad y Política de la UNED. Actualmente es beneficiario de un contrato predoctoral financiado por el VI Plan Propio de Investigación y Transferencia de la Universidad de Sevilla (VI PPIT-US). En la Facultad de Comunicación de la US imparte horas de docencia en la asignatura de Periodismo Político y Económico y es miembro del Grupo de Investigación SEJ-619 "Communication \& Social Sciences" (COM \& SOC). Anteriormente, a nivel profesional ha sido becario de la Comisión Europea, de la Fundación Galicia Europa (organismo de la Xunta de Galicia ante la UE) en Bruselas y del Centro de Investigaciones Sociológicas (CIS). En 2019 realiza su primera estancia de investigación en el extranjero, que tiene lugar en el Institut für Kommunikationsund Medienwissenschaft IfKMW (Institute of Communication and Media Studies) de la Universität Leipzig (Alemania). Sus líneas de investigación se centran en el estudio de la calidad periodística, la información local y los nuevos medios digitales, así como en la comunicación política europea, en lo referente a las políticas de comunicación de la Unión Europea y el reflejo mediático de las mismas. rrivasderoca@us.es

\section{Índice H: 1}

Orcid ID: https://orcid.org/0000-0001-5842-4533

Google Scholar: https://scholar.google.es/citations?user=x1QWEI8AAAAJ\&hl=es

\section{Mar García-Gordillo}

Departamento de Periodismo II. Facultad de Comunicación. Universidad de Sevilla. España.

Mar García Gordillo es Profesora Titular del Departamento de Periodismo II de la Universidad de Sevilla. Miembro del Grupo de Investigación SEJ-619 Communication \& Social Sciences (COM \& SOC). Actualmente es Directora General de Comunicación de la Universidad de Sevilla y anteriormente ha ejercido como Vicedecana de Prácticas y Empresas de la Facultad de 
Comunicación y como Directora del Secretariado de Prácticas en Empresas y Empleo de la Universidad. Actualmente imparte docencia en el Máster Oficial de Comunicación Institucional y Política y en el Máster Oficial de Estudios Europeos. Ha dirigido cinco tesis doctorales, todas ellas calificadas con sobresaliente cum laude (una de las mismas con mención internacional) y es parte del claustro de profesores de Doctorado Interuniversitario de Comunicación de la Universidad de Sevilla. También ha sido la responsable coordinadora de todas las asignaturas de Periodismo Especializado adscritas al Departamento de Periodismo II. Sus líneas de investigación se centran en el estudio de la calidad periodística, la comunicación política internacional y europea, la información local y los nuevos medios digitales. Su índice H es 7 y el $i 106$ (noviembre de 2018). Ha participado como investigadora en el proyecto "La satisfacción de las necesidades informativas de las mujeres. Análisis de la empresa periodística bajo la perspectiva de género" (INVM PR041-07) y actualmente es investigadora del proyecto "Influencers en la comunicación política en España. Análisis de las relaciones entre líderes de opinión 2.0, medios de comunicación, partidos, instituciones y audiencias en el entorno digital" (CSO2017-88620-P).

marggordillo@us.es

\section{Índice H: 7}

Orcid ID: https://orcid.org/0000-0002-9367-0366

Google Scholar: https://scholar.google.es/citations?user=kLc-cAQAAAAJ\&hl=es

\section{Francisco J. Caro-González}

Departamento de Administración de Empresas y Marketing. Facultad de Comunicación. Universidad de Sevilla. España.

Francisco J. Caro González es Licenciado en CC. Económicas y Empresariales y Doctor en Administración de Empresas Imparte docencia en la Facultad de Comunicación desde 1993 en asignaturas relacionadas con la gestión y organización empresas periodísticas y el emprendimiento. También participa o ha participado en diferentes cursos de postgrado oficiales tanto nacionales como extranjeros (Chile, Perú, México, Nicaragua, Panamá o República Dominicana). Entre sus líneas de investigación destacan los estudios de género relacionados con las empresas periodísticas y el emprendimiento, la gestión del cambio en las organizaciones y la metodología de investigación cualitativa. Ha sido investigador principal de un proyecto I+D sobre la perspectiva de género en las empresas periodísticas. Pertenece al grupo "Communication \& Social Sciences". Ha sido investigador principal del proyecto I+D+i (2007-2010) "Satisfacción de las necesidades informativas de las mujeres". Ha participado en diferentes proyectos de investigación competitivos de ámbito nacional como responsable del desarrollo metodológico de los mismos. Ha tenido estancias formativas y de investigación en el extranjero: Estrasburgo (École de Management Europeenne) y París (École Superieure de Commerce); y en España, en la Universidad de Burgos como profesor visitante investigador. Desde 2013 es Director del Laboratorio Ocupacional de la Universidad de Sevilla, responsable de analizar la inserción laboral de los egresados de esta universidad. fjcaro@us.es

Índice H: 11

Orcid ID: http://orcid.org/0000-0002-7261-9377

Google Scholar: $\underline{\text { https://scholar.google.es/citations?user=gpDd14MAAAAJ\&hl=es }}$ 